\title{
Do ultra-orphan medicinal products warrant ultra-high prices? A review
}

This article was published in the following Dove Press journal:

Orphan Drugs: Research and Reviews

22 June 2013

Number of times this article has been viewed

\author{
Eline Picavet ${ }^{\mid}$ \\ David Cassiman ${ }^{2}$ \\ Steven Simoens' \\ 'Department of Pharmaceutical and \\ Pharmacological Sciences, KU Leuven, \\ Leuven, Belgium; ${ }^{2}$ Department of \\ Hepatology, University Hospital \\ Leuven, Leuven, Belgium
}

\begin{abstract}
Ultra-orphan medicinal products (ultra-OMPs) are intended for the treatment, prevention, or diagnosis of ultra-rare diseases, ie, life-threatening or chronically debilitating diseases that affect less than one per 50,000 individuals. Recently, high prices for ultra-OMPs have given rise to debate on the sustainability and justification of these prices. The aim of this article is to review the international scientific literature on the pricing of ultra-OMPs and to provide an overview of the current knowledge on the drivers of ultra-OMP pricing. The pricing process of ultra-OMPs is a complex and nontransparent issue. Evidence in the literature seems to indicate that ultra-OMPs are priced according to rarity and what the manufacturer believes the market will bear. Additionally, there appears to be a trend between the price of an ultra-OMP and the number of available alternatives. Patients, third-party payers, and pharmaceutical companies could benefit from more transparent pricing strategies. With a view to containing health care costs, it is likely that cost-sharing strategies, such as performance-based risk sharing arrangements, will become increasingly more important. However, it is vital that any measures for price control are consistent with the intended goals of the incentives to promote the development of new OMPs. Ideally, a balance must be struck between attaining affordable prices for ultra-OMPs and securing a realistic return on investment for the pharmaceutical industry.
\end{abstract}

Keywords: ultra-orphan medicinal product, ultra-rare disease, pricing

\section{Introduction}

In the European regulation, rare diseases are described as "conditions that occur so infrequently that the cost of developing and bringing to the market a medicinal product to diagnose, prevent, or treat the condition would not be recovered by the expected sales of the medicinal product." In Europe, the maximum prevalence of a rare disease is five cases per 10,000 individuals. ${ }^{1}$ The World Health Organization adopted a definition in which the maximum prevalence of a rare disease is 65 cases per 100,000 individuals. ${ }^{2}$ Ultra-rare diseases constitute an informal subcategory, within rare diseases, to describe very rare diseases. The frequency of ultra-rare diseases is not well defined; consequently, no formal legal definition exists. ${ }^{3}$ The term was first used by the National Institute for Health and Care Excellence (NICE), for a rare disease affecting less than 1000 cases in England and Wales, which corresponds to a prevalence of less than one case per 50,000 individuals. ${ }^{4-8}$ Prior to the regulation, the ultra-orphan market was considered unattractive and unprofitable.

Recent statements seem to indicate that the tide is turning. The pharmaceutical industry, confronted with lagging traditional drug approvals and declining investments, is seeking new sources of income. ${ }^{9,10}$ Spurred by high prices,
Correspondence: Eline Picavet

Department of Pharmaceutical and Pharmacological Sciences, KU Leuven, Herestraat 49, PO Box 52I, 3000 Leuven, Belgium

Tel +3216330149

Fax +3216323468

Email eline.picavet@pharm.kuleuven.be which permits unrestricted noncommercial use, provided the original work is properly cited. 
pharmaceutical companies have moved from traditional blockbusters to niche-busters. ${ }^{11,12}$ Shorter clinical development time, the high level of unmet medical need, and successful regulatory submissions fuelled a turn to targeted medicinal products. ${ }^{12}$ Nowadays, orphan medicinal products (OMPs), intended for the treatment, diagnosis, or prevention of ultra-rare diseases, represent attractive investment opportunities. ${ }^{1,9,10}$ A few OMPs even qualify as blockbusters, as their global annual sales exceed $\$ 1$ billion. ${ }^{10}$

High prices for ultra-OMPs can be traced back to the need to recoup a high cost of research and development (R\&D) from a small number of patients. ${ }^{13}$ Genzyme was the first to charge a high price for imiglucerase, and other ultra-OMPs soon followed. ${ }^{10,14}$ Imiglucerase, an enzyme replacement therapy (ERT) for the treatment of Gaucher's disease, costs between $\$ 100,000$ and $\$ 400,000$ per patient per year. Although there are only 2000 patients in the United States and 6000 patients worldwide, the revenue from imiglucerase approached US $\$ 1.8$ billion in $2009 .{ }^{10,11,15}$ Similarly, agalsidase beta (for the treatment of Fabry disease) and laronidase (for the treatment of mucopolysaccharidosis type I), respectively cost $\$ 300,000$ and $\$ 350,000$ per year per patient. ${ }^{11,16}$ In a study by Orofino, the average of the mean cost per patient across several European countries ranged from $€ 3523$ to $€ 337,501$ for 14 ultra-OMPs. ${ }^{17}$ The yearly cost of eculizumab (for the treatment of paroxysmal nocturnal hemoglobinuria) is the highest, at just under $\$ 500,000$ per patient. ${ }^{9,10}$ In 2010 , eculizumab generated $\$ 541$ million in sales. ${ }^{12}$ Remarkably, eculizumab was originally intended for the treatment of arthritis, and would probably have been priced in the range of similar medicinal products at $\$ 20,000$ per patient per year. ${ }^{18}$ Extraordinary price increases (defined as increases of more than $100 \%$ at a time) have also been documented when established off-label use of a medicinal product became approved. ${ }^{19,20}$ For example, unlicensed use of 3,4-diaminopyridine for the treatment of Lambert-Eaton myasthenic syndrome cost approximately $€ 1000$ per patient per year. The price of the marketed version is $50-70$ times higher. $^{21}$

Prices, often as high as the market will bear, have given rise to arguments on the justification of high prices. ${ }^{22}$ For example, the Dutch government questioned the high prices of some ultra-OMPs for the treatment of hereditary metabolic disorders. ${ }^{23}$ The pricing process of ultraOMPs has been viewed as arbitrary and nontransparent. ${ }^{24}$ Additionally, there is a debate on the sustainability of high prices for ultra-OMPs within the context of current health care systems. ${ }^{12}$
The aim of this article is to review the international scientific literature on the pricing of ultra-OMPs. In that way, we aim to provide an overview of the current knowledge on the drivers of ultra-OMP pricing.

\section{Methods}

The literature review identified studies by searching the following databases: MEDLINE, Embase, Web of Knowledge, EconLit, National Health Service (NHS) Economic Evaluation Database, and Cochrane Database of Systematic Reviews. The following search terms and combinations thereof were used: orphan drug; orphan medicinal product; ultra-orphan drug; ultra-orphan medicinal product; rare disease; ultra-rare disease; rare disorder; ultra-rare disorder; ERT; price; pricing; policies; price-setting; market access; budget; and regulation. The last search was performed on February 28, 2013. For practical reasons, all selected studies were published in English, French, or Dutch. Bibliographies of relevant articles were searched for additional references.

\section{The pricing process of ultra-OMPs}

The pricing of ultra-OMPs has been described as complex and arbitrary. ${ }^{24,25}$ Recently, Michel and Toumi recognized the lack of research on the pricing of OMPs. ${ }^{6}$ Pharmaceutical pricing itself is not an event, but a process of value judgment in which the context is provided by an interplay of factors. ${ }^{26}$ It was observed that the pricing mechanisms for OMPs are essentially similar to those for traditional medicinal products, ie, a price is initially set based on the company's profitability and return on investment and then compared to the reality of the target market. ${ }^{27}$ According to Kolassa, eight factors must be considered: two internal factors relating to (1) company needs (ie, need to recover R\&D costs) and (2) abilities; and six external factors: (3) value (ie, perceived medical benefit); (4) competitive environment (ie, availability and prices of alternative and competing medicinal products); (5) patient and disease characteristics (ie, disease prevalence); (6) reimbursement environment; (7) decision making; and (8) public policy environment. Factors one to four are considered the main drivers in determining price and price changes. ${ }^{24,26} \mathrm{In}$ the following paragraphs, an overview will be given of these different factors relevant to pricing of ultra-OMPs.

\section{Internal factors: company needs and company abilities}

As with any medicinal product, its price is an attempt to recoup investments in $\mathrm{R} \& \mathrm{D} .{ }^{17}$ On the one hand the development cost of an OMP, on average $\$ 90$ million, 
amounts to only $25 \%$ of the cost of development of traditional medicinal products. Due to the smaller patient population, clinical trials for ultra-OMPs are much smaller and therefore likely cheaper than traditional clinical trials. ${ }^{11,28}$ On the other hand, the price of one ultra-OMP also factors in R\&D expenditures for hundreds or thousands of compounds that failed to achieve marketing authorization. Pharmaceutical drug development is a risky process; approximately a third of all compounds fail Phase III trials..$^{29,30}$ Over the last years, increased pipeline attrition has added to increased $R \& D$ expenditures. ${ }^{12}$ Additionally, expensive surveillance programs are often imposed by regulatory authorities as a post marketing commitment. ${ }^{31}$ Miyamoto et al suggested that cost management, through increased use of surrogate endpoints and expedited review, could decrease development costs to $\$ 28$ million..$^{28}$ Nevertheless, development costs are still considered the highest for the rarest of diseases. ${ }^{2}$ An independent study estimated the development cost of imiglucerase at less than $\$ 30$ million. ${ }^{24}$ For some 'repurposed' medicines, the effectiveness evidence was published prior to the application for orphan designation. In those cases, the costs of R\&D are believed to be negligible. Nevertheless, upon comparing Belgian hospital prices per defined daily dose of the medicine for the common indication versus the rare indication, up to a 200 -fold price difference was reported. ${ }^{32}$ Finally, several patient advocacy groups actively fund and support clinical development. For example, the American Cystic Fibrosis Foundation has invested more than $\$ 300$ million towards the development of new treatments for cystic fibrosis. ${ }^{11}$

Worldwide, legislation is in place to stimulate the development of OMPs. Incentives include free protocol assistance, fee reductions, tax credits, expedited review by registration authorities, and granting a period of marketing exclusivity. ${ }^{1,33}$ In Europe, the overall fee reductions for all OMPs amounted to $€ 6,840,900$ in $2005 .{ }^{6}$ These incentives increase the commercial value of OMPs by reducing R\&D expenses and shortening time-to-market. ${ }^{19,34}$ Despite these incentives to promote the development of OMPs, there is no guarantee that an OMP will become available or remain available on the market. ${ }^{15}$

Many ultra-OMPs are biotechnological products, manufactured through complex and expensive processes. ${ }^{14}$ The high cost of acquiring and/or manufacturing the active ingredient is often put forward to justify the price of an OMP. ${ }^{11}$ Nonetheless, production costs and molecular complexity do not seem to correlate with the prices of OMPs. After all, changes and advances in the production method of imiglucerase for Gaucher's disease did not lead to a reduc- tion in price. Monoclonal antibodies, of similar molecular and manufacturing complexity, are sold at far lower or far higher prices. ${ }^{24}$

At the same time, opportunities arise when marketing in small target populations. The costs associated with the sale of OMPs are low. ${ }^{11}$ There are indeed some extra costs associated with setup, such as building referral networks, training physicians, and supporting patient advocacy groups, ${ }^{2}$ however, marketing costs are lowered by using social media for direct-to-patient advertising through patient advocacy groups. ${ }^{10,11}$

Finally, market exclusivity and/or patent protection also enable the marketing authorization holder to set a high price. Additionally, there is no oversight body to control prices. ${ }^{19,24}$ Corporate strategy with respect to pricing ultra-OMPs can therefore be summarized as setting the price as high as the market will bear. ${ }^{19,22}$

\section{External factor: value}

The concept of value or therapeutic benefit is dependent on factors such as seriousness of condition, level of unmet needs, and incremental clinical benefit. ${ }^{26}$ By definition, rare diseases are life-threatening or serious chronically debilitating diseases for which no or few alternative treatments are available. ${ }^{1}$ The level of incremental clinical benefit, however, is usually not fully established when the price is set. In most cases there is limited information on the natural course of an ultra-rare disease. Additionally, in small populations, difficulties in generating evidence to demonstrate clinical benefit arise. Roos et al claim that the therapeutic benefit of an OMP does not correlate with its price. ${ }^{24}$

\section{External factor: competitive environment} Competition during the period of market exclusivity During the period of market exclusivity, no similar product can be marketed for the same indication. ${ }^{6,10,31}$ The first applicant can lose market exclusivity to the benefit of the second, if the second product is superior in terms of safety or efficacy. ${ }^{6}$ Sponsors of dissimilar products can apply for a separate marketing authorization, but are often discouraged from doing so by the small target population and high costs. ${ }^{2,6}$ In one exceptional case, agalsidase beta and agalsidase alfa were both approved in Europe, through a whim of administrative flexibility, for the treatment of Fabry disease. ${ }^{15}$ For some of the most common rare diseases, such as pulmonary arterial hypertension, up to four different OMPs are available on the European market. By contrast, the very small size of the target population brings about little competition in the 
field of ultra-rare diseases..$^{2,9,35,36}$ Nevertheless, premium prices have attracted some competition, even in very small markets. For example, in the United States, both imiglucerase and taliglucerase alfa are available for the treatment of Gaucher's disease. ${ }^{10}$

In some cases, a monopolistic situation is created in which only one medicinal product is available for a single indication, spurring manufacturers to dictate high prices. ${ }^{6,10,19}$ However, results on that issue contradict each other; only a trend that is not significant has been reported between the number of available alternatives for a rare disease and the price of OMPs. ${ }^{25}$ Furthermore, an analysis investigated the influence of awarding orphan designation status (and thus market exclusivity at the time of marketing authorization) on the price setting of medicines for rare indications. Upon comparing Belgian hospital prices per defined daily dose of 28 designated OMPs and 16 comparable non-designated medicines for rare disease, a significantly higher median price was recorded for the former (€138.56) compared to the latter (€16.55). ${ }^{37}$ In contrast, no statistically significant difference in price distribution was found between French hospital prices of 41 medicines with, and 17 medicines without, orphan designation. ${ }^{38}$ On that account, market exclusivity and lack of alternatives are likely associated with higher prices for medicinal products for rare diseases, but not as the only sources of higher prices..$^{37,38}$ Article 8.2 of the regulation on OMPs allows for the period of market exclusivity to be reduced to six years. ${ }^{1}$ Member States can invoke the application of this procedure for a highly profitable OMP with a view to lowering its price. At that point however, immediate price decreases due to direct competition are unlikely. ${ }^{39}$

\section{Competition from generic medicinal products}

Competition from generic medicinal products can only occur when all protection on the originator medicine has elapsed. ${ }^{40}$ Besides patent protection, OMPs also benefit from a period of market exclusivity. Market exclusivity may give exclusivity beyond the patent, therefore sustaining return on investment after patent expiration. ${ }^{36}$ Even if the period of market exclusivity is reduced, most medicines will still be protected by patents. ${ }^{41}$ In Europe several OMPs (imatinib, bosentan) have lost or will soon lose both their market exclusivity and patent protection..$^{42}$ Recently, the Committee for Medicinal Products for Human Use adopted a positive opinion on marketing authorization for a generic version of imatinib. ${ }^{43}$ Potential price decreases, due to entry of generic OMPs, are difficult to predict. ${ }^{42}$ Prices of traditional generic medicines tend to be $10 \%-80 \%$ lower than those of originator medicines. ${ }^{44}$ In the US, generic prices of a sample of 12 OMPs were on average $50 \%$ lower than the original medicine. ${ }^{42}$ Biosimilars could be sold at a price $10 \%-30 \%$ lower than the originator. ${ }^{45}$ However, the biosimilar velaglucerase alfa is priced higher than the originator imiglucerase. It is also likely that competing manufacturers, in order to maximize their own revenue, will set their price just below the price of the originator medicine. Estimates show that at least five competitors are needed to achieve significant price reductions, an unlikely scenario in the ultra-OMP market. . $^{241}$

On that account, it remains to be seen whether competition in the field, from other OMPs or generic versions, can lead to price reductions and savings in the health care budget. Nevertheless, competition may stimulate future innovation and could help in reducing critical supply shortages of lifesaving medicines. ${ }^{45}$

\section{External factor: patient and disease characteristics}

Because ultra-OMPs target small populations, high prices are needed to recoup (volume-independent) R\&D expenditures. ${ }^{6,13}$ As such, there is an inverse correlation between the price per capita of an ultra-OMP and the prevalence of the disease; the rarer the disease, the more expensive the treatment. In other words, the yearly cost per patient is inversely related to the prevalence of the disease. ${ }^{25,27,31,46} \mathrm{The}$ inverse relationship, however, is not linear and there are exceptions; some prices of medicinal products, with similar prevalence, differ as much as sevenfold. ${ }^{24}$

The first symptoms of an ultra-rare disease usually occur during childhood. ${ }^{14}$ For example, Fabry disease is characterized by an accumulation of a glycolipid within various organs, leading to severe manifestations starting in early childhood. Therefore, some ultra-orphan lysosomal storage disorders often require life-long ERTs. ${ }^{7}$ In the case of ERTs, the cost of treatment also directly relates to the dose of the treatment. ${ }^{15}$ Thus far, the cost-effectiveness of lower dosages has not been established and, therefore, the optimal price is not known. On the other hand, ERTs also generate some (marginal) savings, as patients may require less or no symptomatic care. ${ }^{14}$

Evidence also shows that the price of an ultra-OMP is set according to the prevalence of a single, ie, the initial, indication. ${ }^{47}$ Indeed, companies are encouraged to develop a medicinal product for a rare indication and promote its use. Thereafter, new indications are sought and the OMP is 
marketed at the high initial price, generating disproportionate returns. ${ }^{11,47}$ For some OMPs, the target population is broad; for example, imatinib is now used for both orphan as well as non-orphan oncolytic indications. ${ }^{10,31}$ In a study by Kesselheim et al, statistically significant non-orphan and off-label use was found in three of four top-selling OMPs studied. ${ }^{48}$ Nonetheless, (off-label) expansion is unusual for ultra-OMPs, as these therapies mostly target disease-specific pathways. $^{2}$

In a study by Aballea, the association between several disease-related and drug-related variables and the prices of 51 OMPs in five European countries was studied using regression analysis. However, no significant assocation was found between any of the disease-specific variables (disease area, prognosis, age and vulnerability of target population, seriousness, number of available treatments, and course of illness) or drug-specific variables (year of approval, trial size, number of trials, comparator in trial, Anatomical Therapeutical Chemical Classification System [ATC] code, evidence of benefit) and price. A not statistically significant association was found between high prices and low prevalence and low number of treatment alternatives. ${ }^{25}$

\section{External factor: reimbursement environment}

In most European countries, ultra-OMPs are fully reimbursed, whereas in the United States and Canada copayments for patients exist. ${ }^{6,49}$ As such, high prices for ultra-OMPs have a direct (through high financial costs) and/or indirect (through the fear of having funding for the treatment withdrawn) effect on patient access. ${ }^{24}$ Patients can get access to ultra-OMPs via health insurance or alternatively through company funded patient assistance programs. ${ }^{10}$

The reimbursement of ultra-OMPs can create conflicts between the rights of individuals (ie, right of access to treatment) and overall health of a society. On the one hand, the principles of equity and no abandonment imply that treatments for life-threatening diseases should be made available, regardless of their cost. The fact that for most ultra-rare disease no alternative treatment is available also underlines the high therapeutic need. ${ }^{50}$ On the other hand, society allocates health budget to interventions with a view to maximizing the health of the population as a whole. As such, reimbursement of expensive ultra-OMPs for a minority of patients brings about missed opportunities in treating common illnesses with inexpensive medicinal products. ${ }^{4,16,51}$ Ideally, reimbursement decisions should reflect public preferences, but at the moment, preference towards reimbursement of ultra-OMPs is not fully evident. ${ }^{52}$ Moreover, in times of economic hardship, there is increasing pressure to contain health care costs.

Ultra-OMPs are seldom cost-effective, on the one hand due to their high price, and on the other hand because of the uncertainty surrounding the long-term effectiveness and clinical benefit. ${ }^{4,5,14}$ Consequently, ultra-OMPs are expensive per unit of healthy life years gained. ${ }^{20}$ If they are judged against traditional thresholds, ultra-OMPs are unlikely to meet them. ${ }^{11,35}$ The probability even declines with decreasing prevalence. ${ }^{35,53}$ Nevertheless, the willingness-to-pay for ultraOMPs by patients, the population, and/or third party payers is high; on the one hand, this is because of the seriousness of the disease and the lack of suitable alternatives, and on the other hand, because one can easily identify with ultra-rare disease patients. ${ }^{11,19}$ Evidence indicates that the public prefers to offer treatments to those with the worst initial health state, even if this is not a cost-effective allocation of resources. ${ }^{13}$ The majority of 27 participants of the Citizen's Council set up by NICE in England and Wales voted to pay premium prices for medicines to treat very rare conditions. ${ }^{7,14}$ Because of the low impact on the budget of the NHS, NICE does not evaluate ultra-OMPs. Recently, a new Advisory Group for National Specialized Services was created, with a mandate to work out a new system to assess highly specialized services such as ultra-OMPs. The assessment consists of a two-stage procedure, where the suitability of the drug for national commissioning is verified in the first stage, and the drug is assessed in the second phase against 12 criteria that belong to the four groups of health gain, societal value, reasonable cost, and best clinical practice. ${ }^{54} \mathrm{As}$ such, this is an application of multi-criteria decision analysis, an assessment system based on weighted evaluation criteria. An innovative assessment system for OMPs based on several weighted evaluation criteria (eg, severity, disease severity) has been proposed by Hughes-Wilson et al. If in fact society reveals a preference in treating ultra-rare diseases, multicriteria decision analysis allows decision-makers to evaluate treatments based on a predefined ranking system. ${ }^{35}$ An ethical framework has also been proposed in which a fair share of health care resources are allocated to rare diseases. The model is based both on budgetary insulation, which allows access to treatment for certain patients, and on possible access for a few randomly selected patients. ${ }^{55}$

\section{External factor: decision making and public policy}

At present, regulatory restrictions and procedures for pricing and reimbursement vary in each country; therefore, prices 
for ultra-OMPs vary from one country to another. ${ }^{27,56}$ For example, Eastern European countries may have the highest prices (based on purchasing power) according to one study. ${ }^{49}$ Pharmaceutical companies often opt to market new medicinal products first in countries with free-pricing systems, such as Germany. ${ }^{24,41}$ It is however also possible to set high prices in some countries where pricing is more restricted (ie, Portugal, Spain). For example, in France a system of Temporary Authorization for Use (ATU) exists to make a medicinal product available and fully reimbursed before marketing authorization. The price and indication during the time of ATU should ideally reflect future authorized indications and price. ${ }^{57}$ However, some manufacturers are inclined to set a high price in the ATU system, in an (usually successful) attempt to retain high price after marketing authorization. ${ }^{24,41}$

Local pricing and reimbursement policies do not always align with wishes of patients, society, and pharmaceutical companies. For example, the logic of cost-effectiveness applied by third-party payers conflicts with the needs of ultra-rare disease patients for speedy access to treatment. ${ }^{13,19}$ Additionally, there is often pressure from patient organizations and society to provide treatments. ${ }^{24}$ In that debate, pharmaceutical companies highlight the (perception) of unmet need and the well-being of patients. ${ }^{20,25}$ From a point of view of the pharmaceutical industry, it also appears as if third-party payers are much too focused on containing health care costs, and in that way are unwilling to reward pharmaceutical innovation. ${ }^{56}$

Third-party payers are increasingly concerned with escalating health care costs. ${ }^{45}$ Prices for ultra-OMPs are high, and the system of third-party payers provides limited incentives for physicians and patients to be cost-conscious. ${ }^{19,58}$ Although ultra-OMPs are expensive per patient, overall drug expenditure is expected to be limited because of the narrowness of the market. ${ }^{20,27}$ However, when combined, a large number of patients can still have a large impact on health care budgets., A Belgian study showed that the impact of OMPs is substantial, ie, amounting to $1.9 \%$ of pharmaceutical expenditure in 2008 . All three growth scenarios predicted a significant rise in expenditure in the future ${ }^{59}$ Orofino et al anticipated that, although expenditure in OMPs will continue to increase, it will remain a low percentage of overall pharmaceutical expenditure. ${ }^{17}$ The most recent analysis by Schey et al predicted that the expenditure on OMPs, as a proportion of total pharmaceutical expenditure, is likely to plateau between $4 \%-5 \%{ }^{42}$ To date, no specific data estimating the budget impact of ultra-OMPs are available to the best of the authors' knowledge.
At the moment, European member states have the responsibility to revise pricing for ultra-OMPs, but they often have limited power to negotiate lower prices. ${ }^{6,24}$ For example, in France, treatments for Fabry diseases are procured under special programs, of which the details are unavailable to the public. ${ }^{49}$ Prices of OMPs that are distributed through the hospital pharmacy can also be negotiated between the manufacturer and the hospitals. ${ }^{31}$ In some cases, (virtual) centers of expertise for ultra-rare diseases can also attempt to purchase ultra-OMPs at a lower price. ${ }^{3}$ For example, through direct purchases of ultra-OMPs from the manufacturer or supplier, commercial discounts (such as price reductions), rebates, or in some cases cost-free products, can be obtained. ${ }^{60}$

\section{Sustainability and ways forward}

High prices for ultra-OMPs have a negative effect on the pharmaceutical industry's reputation, as the general population considers it indecent to profit from the misfortunes of others. ${ }^{19,58}$ But the expectations of the general public are at odds with itself; on the one hand they expect the industry to develop new life-saving medicines, on the other hand there is a taboo against commercialization and profit seeking in health care..$^{58}$

Pricing of ultra-OMPs is an important and delicate issue as it has a direct effect on patient access to health care. ${ }^{19}$ While there may be benefits for patients, high prices fuel the demand for price controls. However, without appropriate benchmarks, it is difficult to assess whether the price of an ultra-OMP is too high or too low relative to its value. ${ }^{47}$ Revenue is approximated by multiplying market size and the price of a medicinal product; however, market size is only roughly estimated, as there are few reliable data on prevalence of ultra-rare diseases. ${ }^{28}$ Consequently, it is equally difficult to calculate the profitability of an ultra-OMP, roughly defined as what a company gains of benefit from one product, especially if there is more than one indication. ${ }^{39,41}$ The industry would benefit from appropriate benchmarks and a clear definition of profitability. ${ }^{47}$ In Japan, companies with profitable OMPs (ie, with annual profits over JPY 100 million) pay a $1 \%$ tax on sales with a view to repaying received benefits. ${ }^{61}$

European member states also have a different ability to pay for high-priced ultra-OMPs. Differential pricing is an instrument according to which a pharmaceutical manufacturer establishes a higher price for the drug in a more affluent country, but accepts a lower drug price in a country where consumer demand is more responsive to price changes. ${ }^{62}$ The application of differential pricing to ultra-OMPs may enhance 
equality of access to these innovative pharmaceuticals for unmet medical needs across Europe.

According to McCabe et al, there is also scope for price negotiations, for example, by refusing to pay exorbitant prices or by making demands on discounts. ${ }^{9,63}$ However, these price controls need to be consistent with the intended goals of the incentives to promote the development of new OMPs. ${ }^{19}$ Price controls create short-term benefits, but they could also create shortages and could take away incentives to invest in the development of new OMPs. ${ }^{19}$

The uncertainty of the cost-effectiveness often hampers timely access to new ultra-OMPs. New market access agreements, such as performance-based risk sharing arrangements, offer a unique way to dealing with the unproven long-term effectiveness of expensive ultra-OMPs. ${ }^{53}$ If after a certain period of time the clinical evidence is not sufficiently convincing, a decrease in price can be considered. ${ }^{47,64}$ In February 2013, there were eight OMPs with approved Patient Access Schemes and recommended by NICE for use in the NHS. ${ }^{65}$ Although experience of employing new market access agreements in the field of ultra-rare disease is still limited, it is likely that these strategies will become increasingly more important. Nonetheless, it is vital to safeguard transparency on funding, privacy, patient selection, and governance. ${ }^{66}$ For example, new market access agreements based on effectiveness for the treatment of mucopolysaccharidosis IV, an ultrarare disease, were found to be potentially disadvantageous for slowly progressive patients. ${ }^{13}$ Agreements must also allow for flexibility; as the therapeutic context may evolve over time, it is vital to continuously match the research design to current uncertainties. ${ }^{67,68}$ Alas, new market access agreements are also costly; there are considerable costs associated with monitoring, negotiation, and evaluation. From a societal point of view, new market access agreements can be considered as an investment in data collection to inform pricing arrangements. ${ }^{68}$

\section{Conclusion}

A lot of vagueness still surrounds the pricing mechanisms for ultra-OMPs. The literature appears to indicate that ultra-OMPs are priced according to rarity and what the manufacturer believes the market will bear. Patients, third-party payers, and pharmaceutical companies could benefit from more transparent pricing strategies. Therefore, future research should continue to focus on the different factors that influence pricing of ultra-OMPs. Ideally, a balance must be struck between attaining affordable prices for ultra-OMPs and securing a realistic return on investment for the pharmaceutical industry.

\section{Disclosure}

The authors report no conflicts of interest in this work. No sources of funding were used to assist in the preparation of this manuscript.

\section{References}

1. European Commission. Regulation (EC) No 141/2000 of the European Parliament and of the Council of 16 December 1999 on orphan medicinal products. Official Journal of the European Communities. 2000;L18(1):1-5.

2. Zitter M. Managing drugs for rare genetic diseases: trends and insights. Manag Care. 2005;14(2):52-54, 57-60, 63-64, quiz 66-67.

3. Hennekam RC. Care for patients with ultra-rare disorders. Eur J Med Genet. 2011;54(3):220-224.

4. Dear JW, Lilitkarntakul P, Webb DJ. Are rare diseases still orphans or happily adopted? The challenges of developing and using orphan medicinal products. Br J Clin Pharmacol. 2006;62(3):264-271.

5. Moore DF, Ries M, Forget EL, Schiffmann R. Enzyme replacement therapy in orphan and ultra-orphan diseases: the limitations of standard economic metrics as exemplified by Fabry-Anderson disease. Pharmacoeconomics. 2007;25(3):201-208.

6. Michel M, Toumi M. Access to orphan drugs in Europe: current and future issues. Expert Rev Pharmacoecon Outcomes Res. 2012;12(1):23-29.

7. Miles KA, Packer C, Stevens A. Quantifying emerging drugs for very rare conditions. QJM. 2007;100(5):291-295.

8. National Institute for Health and Care Excellence. Appraising Orphan Drugs [updated April 14, 2008]. London: National Institute for Health and Care Excellence; 2008. Available from: http://www.nice.org.uk/ niceMedia/pdf/smt/120705item4.pdf. Accessed May 7, 2013.

9. Daly R. Duel over discounts. Pharma, providers at odds over 'orphan drugs'. Mod Healthc. 2012;42(4):30-31.

10. Phillips MI. Big Pharma's new model in orphan drugs and rare diseases. Expert Opinion on Orphan Drugs. 2013;1(1):1-3.

11. Côté A, Keating B. What is wrong with orphan drug policies? Value Health. 2012;15(8):1185-1191.

12. Meekings KN, Williams CS, Arrowsmith JE. Orphan drug development: an economically viable strategy for biopharma R\&D. Drug Discov Today. 2012;17(13-14):660-664.

13. Schlander M, Beck M. Expensive drugs for rare disorders: to treat or not to treat? The case of enzyme replacement therapy for mucopolysaccharidosis VI. Curr Med Res Opin. 2009;25(5):1285-1293.

14. National Institute for Health and Care Excellence. NICE Citizens Council Report: Ultra Orphan Drugs [updated Nov 2004]. London: National Institute for Health and Care Excellence; 2008. Available from: http://www.nice.org.uk/niceMedia/pdf/Citizens_Council_Ultraorphan. pdf. Accessed Mar 2013.

15. Deegan PB, Cox TM. Imiglucerase in the treatment of Gaucher disease: a history and perspective. Drug Des Devel Ther. 2012;6:81-106.

16. Boy R, Schwartz IV, Krug BC, et al. Ethical issues related to the access to orphan drugs in Brazil: the case of mucopolysaccharidosis type I. J Med Ethics. 2011;37(4):233-239.

17. Orofino J, Soto J, Casado MA, Oyagüez I. Global spending on orphan drugs in France, Germany, the UK, Italy and Spain during 2007. Appl Health Econ Health Policy. 2010;8(5):301-315.

18. Herper M. The World's Most Expensive Drugs [webpage on the internet]. New York: Forbes; 2010 [cited Mar 2013]. Available from: http://www.forbes.com/2010/02/19/expensive-drugs-cost-businesshealthcare-rare-diseases.html. Accessed February 21, 2013.

19. Hemphill TA. Extraordinary pricing of orphan drugs: is it a socially responsible strategy for the US pharmaceutical industry? Journal of Business Ethics. 2010;94(2):225-242.

20. Davies JE, Neidle S, Taylor DG. Developing and paying for medicines for orphan indications in oncology: utilitarian regulation vs equitable care? Br J Cancer. 2012;106(1):14-17. 
21. Nicholl DJ, Hilton-Jones D, Palace J, et al. Open letter to prime minister David Cameron and health secretary Andrew Lansley. BMJ. 2010;341:c6466.

22. Samson K. Orphan economics: the downside of supplyside pharmacology. Ann Neurol. 2008;64(3):A13-A16.

23. Sheldon T. Dutch doctors call for EU evaluation of cost effectiveness of high cost orphan drugs. BMJ. 2012;345:e5461.

24. Roos JC, Hyry HI, Cox TM. Orphan drug pricing may warrant a competition law investigation. BMJ. 2010;341:c6471.

25. Aballea S, Toumi M, Vataire AL, Millier A, Lamure M. Quantitative Analysis of the Influence of Disease and Product Characteristics on Orphan Drug Prices in Europe. Value in Health. 2010;13(3):A82.

26. Mycka JM, Dellamano R. ISPOR short course: Elements of Pharmaceutical/Biotech Pricing. Proceedings of the ISPOR 13the Annual European Congres; November 6-9, 2010; Prague, Czech Republic.

27. Alcimed. Study on orphan drugs. Phase I: Overview of the conditions for marketing orphan drugs in Europe. Paris: Alcimed; 2004. Available from: http://ec.europa.eu/health/files/orphanmp/doc/pricestudy/final_final_report_part_1_web_en.pdf. Accessed February 11, 2013.

28. Miyamoto BE, Kakkis ED. The potential investment impact of improved access to accelerated approval on the development of treatments for low prevalence rare diseases. Orphanet J Rare Dis. 2011;6:49.

29. Tambuyzer E. Rare diseases, orphan drugs and their regulation: questions and misconceptions. Nat Rev Drug Discov. 2010;9(12): 921-929.

30. DiMasi JA, Hansen RW, Grabowski HG. The price of innovation: new estimates of drug development costs. J Health Econ. 2003;22(2): 151-185.

31. Simoens S. Pricing and reimbursement of orphan drugs: the need for more transparency. Orphanet J Rare Dis. 2011;6:42.

32. Simoens S, Picavet E, Cassiman D, Dooms M. What price do we pay for repurposing medicines for rare diseases? Value Health. 2012;15(4): A15-A16.

33. FDA.gov [homepage on the Internet]. Code of Federal Regulation Title 21 Part 316 Orphan Drugs. The Federal Register; 2012 [updated December 29, 1992; cited November 14, 2012]. Available from: http:// www.accessdata.fda.gov/scripts/cdrh/cfdocs/cfCFR/CFRSearch. cfm?CFRPart=316. Accessed November 14, 2012.

34. Ferner RE, Hughes DA. The problem of orphan drugs. BMJ. 2010; 341:c6456.

35. Hughes-Wilson W, Palma A, Schuurman A, Simoens S. Paying for the Orphan Drug System: break or bend? Is it time for a new evaluation system for payers in Europe to take account of new rare disease treatments? Orphanet J Rare Dis. 2012;7(1):74.

36. Thomson Reuters. The Economic Power of Orphan Drugs. New York: Thomson Reuters; 2012. Available from: http://thomsonreuters.com/ content/science/pdf/orphan_drugs.pdf. Accessed January 16, 2013.

37. Picavet E, Dooms M, Cassiman D, Simoens S. Drugs for rare diseases: influence of orphan designation status on price. Appl Health Econ Health Policy. 2011;9(4):275-279.

38. Degrassat-ThéasA, Paubel P, Parent de Curzon O, et al. Is orphan designation a driver of orphan drug pricing? Value Health. 2012; 15(7):A302.

39. Alcimed. Study on Orphan Drugs. Phase II Considerations on the Application of Article 8.2 of EC Regulation No 141/2000 Concerning Orphan Drugs. Paris: Alcimed; 2004. Available from: http://ec.europa. eu/health/files/orphanmp/doc/pricestudy/final_final_report_part_2_ web_en.pdf. Accessed February 11, 2013.

40. Dylst P, Vulto A, Simoens S. Overcoming challenges in market access of generic medicines in the European Union. Journal of Generic Medicines. 2012;9(1):21-28.

41. O'Donnell P. Paying the price of being an orphan. Applied Clinical Trials. 2005;14(1):32.

42. Schey C, Milanova T, Hutchings A. Estimating the budget impact of orphan medicines in Europe: 2010-2020. Orphanet J Rare Dis. 2011;6:62.
43. ESMO.org [homepage on the Internet]. European Society for Medical Oncology. European Medicines Agency recommends granting a marketing authorization to Imatinib Actavis for adult patients with $\mathrm{PH}+$ CML in blast crisis [updated February 25, 2013; cited February 26, 2013]. Lugano: European Society for Medical Oncology; 2013. Available from: http://www.esmo.org/no_cache/view-news.html?tx ttnews \%5Btt_news $\% 5 \mathrm{D}=1830 \& \mathrm{tx} \_$ttnews $\% 5 \mathrm{BbackPid} \% 5 \mathrm{D}=585 \& \mathrm{c}$ Hash=11975deed6. Accessed February 26, 2013.

44. Simoens S, De Coster S. Sustaining Generic Medicines Markets in Europe. Leuven: Research Centre for Pharmaceutical Care and Pharmaco-economics; 2006. Available from: http://212.85.101.126/ images/publikacje/7_pl.pdf. Accessed January 8, 2013.

45. Hyde R, Dobrovolny D. Orphan drug pricing and payer management in the United States: Are we approaching the tipping point? American Health and Drug Benefits. 2010;3(1):15-23.

46. Messori A, Cicchetti A, Patregani L. Orphan drugs. Relating price determination to disease prevalence. BMJ. 2010;341:c4615.

47. Kanavos P, Nicod E. What is wrong with orphan drug policies? Suggestions for ways forward. Value Health. 2012;15(8):1182-1184.

48. Kesselheim AS, Myers JA, Solomon DH, Winkelmayer WC, Levin R, Avorn J. The prevalence and cost of unapproved uses of top-selling orphan drugs. PLoS One. 2012;7(2):e31894.

49. Blankart CR, Stargardt T, Schreyögg J. Availability of and access to orphan drugs: an international comparison of pharmaceutical treatments for pulmonary arterial hypertension, Fabry disease, hereditary angioedema and chronic myeloid leukaemia. Pharmacoeconomics. 2011;29(1):63-82.

50. Picavet E, Dooms M, Cassiman D, Simoens S. Orphan Drugs for Rare Diseases: Grounds for Special Status. Drug Development Research. 2012;73(3):115-119.

51. Simoens S, Cassiman D, Dooms M, Picavet E. Orphan drugs for rare diseases: is it time to revisit their special market access status? Drugs. 2012;72(11):1437-1443.

52. McCabe C. Balancing economic, ethical and equity concerns in orphan drugs and rare diseases. European Journal of Hospital Pharmacy Practice. 2010;16(4):22-25.

53. Hughes DA, Tunnage B, Yeo ST. Drugs for exceptionally rare diseases: do they deserve special status for funding? QJM. 2005;98(11):829-836.

54. NHS Advisory Group for National Specialised Services [homepage on the Internet]. Decision-making framework for making recommendations on national commissioning. London: National Specialised Commissioning Team; 2010 [updated 2010; cited January 29, 2013]. Available from: http://www.specialisedservices.nhs.uk/document/ decision-making-framework-making-recommendations-on-nationalcommissioning. Accessed January 29, 2013.

55. Pinxten W, Denier Y, Dooms M, Cassiman JJ, Dierickx K. A fair share for the orphans: ethical guidelines for a fair distribution of resources within the bounds of the 10-year-old European Orphan Drug Regulation. J Med Ethics. 2012;38(3):148-153.

56. Cueni TB. Can Europe afford innovation? Eurohealth. 2008;14(2): $8-10$.

57. Hensen M, Heemstra H, Meijboom M, Doreau C. Early access: analysis of the French ATU system. Value Health. 2010;13(7):A408.

58. Maitland I. Priceless goods: how should life-saving drugs be priced? Bus Ethics Q. 2002;12(4):451-480.

59. Denis A, Mergaert L, Fostier C, Cleemput I, Simoens S. Budget impact analysis of orphan drugs in Belgium: estimates from 2008 to 2013. J Med Econ. 2010;13(2):295-301.

60. Habl C, Bachner F. Initial investigation to Assess the Feasibility of a Coordinated System to Access Orphan Medicines. Vienna: European Medicine Information Network (EmiN€t); 2011 [updated May 2011; cited February 14, 2013]. Available from: http://ec.europa.eu/enterprise/ sectors/healthcare/files/docs/access_orphans_initialinvest_052011_ en.pdf. Accessed February 13, 2013.

61. Chueng RY, Cohen JC, Illingworth P. Orphan drug policies: implications for the United States, Canada, and developing countries. Health Law J. 2004;12:183-200. 
62. Yaday P. Differential Pricing for Pharmaceuticals. Review of Current Knowledge, New Findings And Ideas for Action. Zarazoga: MIT-Zaragoza International Logistics Program; 2010 [updated 2010; cited March 27, 2013]. Available from: http://pdpaccess.org/downloads/resources/ pricing/Differential\%20Pricing_Yadav.pdf. Accessed March 27, 2013.

63. McCabe C, Stafinski T, Menon D. Is it time to revisit orphan drug policies? BMJ. 2010;341:c4777.

64. Cook JP, Vernon JA, Manning R. Pharmaceutical risk-sharing agreements. Pharmacoeconomics. 2008;26(7):551-556.

65. National Institute for Health and Care Excellence. List of technologies with approved Patient Access Schemes, recommended by NICE for use in the NHS. London: National Institute for Health and Care Excellence; 2013 [updated February 22, 2013; cited May 7, 2013]. Available from: http://www.nice.org.uk/aboutnice/howwework/paslu/ListOfPatient AccessSchemesApprovedAsPartOfANICEAppraisal.jsp. Accessed May 7, 2013.
66. Adamski J, Godman B, Ofierska-Sujkowska G, et al. Risk sharing arrangements for pharmaceuticals: potential considerations and recommendations for European payers. BMC Health Serv Res. 2010; 10:153.

67. Owen A, Spinks J, Meehan A, et al. A new model to evaluate the long-term cost effectiveness of orphan and highly specialised drugs following listing on the Australian Pharmaceutical Benefits Scheme: the Bosentan Patient Registry. J Med Econ. 2008;11(2):235-243.

68. Garrison LP Jr, Towse A, Briggs A. Performance-based risk-sharing arrangements - good practices for design, implementation, and evaluation: ISPOR good practices for performance-based risk-sharing arrangements task force report. Value Health. Epub May 17, 2013.

\section{Publish your work in this journal}

Orphan Drugs: Research and Reviews is an international, peer-reviewed, open access journal publishing original research, reports, reviews and commentaries on all areas of the design and development of orphan drugs for the treatment of rare diseases through to clinical applications Clinical outcomes, patient safety, and programs for the development and effective, safe, and sustained use of medicines will be a feature of the journal. The manuscript management system is completely online and includes a very quick and fair peer-review system, which is all easy to use. Visit http://www.dovepress.com/testimonials.php to read real quotes from published authors.

Submit your manuscript here: http://www.dovepress.com/orphan-drugs-research-and-reviews-journal 